\title{
Role of spoT-dependent ppGpp accumulation in the survival of light-exposed starved bacteria
}

\author{
Lan Gong, Kathy Takayama and Staffan Kjelleberg
}

School of Microbiology and Immunology, The University of New South Wales, Sydney 2052, Australia
Author for correspondence: Staffan Kjelleberg. Tel: +6129385 2102. Fax: +61293851779. e-mail: s.kjelleberg@unsw.edu.au

In bacteria, cytoplasmic levels of the effector nucleotide ppGpp are regulated in response to changes in growth conditions. This study describes the involvement of SpoT-mediated ppGpp accumulation in the survival of lightexposed bacteria during fatty acid starvation. In contrast to isogenic wild-type strains and relA mutants, the 'Vibrio angustum' S14 spoT and Escherichia coli relA spot mutants displayed significant losses in viability in response to cerulenin-induced fatty acid starvation under cool-white fluorescent light. However, when starvation experiments were performed in complete darkness, or under light filtered through a UV-resistant perspex sheet, only a minor decline in viability was observed for the wild-type and mutant strains. This finding indicated that the lethal effect was mediated by weak UV emission. In contrast to the $E$. coli relA spoT mutant, which lacks ppGpp, the ' $V$. angustum' S14 spoT mutant exhibited higher ppGpp levels and lower RNA synthesis rates during fatty acid starvation, features that might be correlated with its lethality. In agreement with this finding, fatty acid starvation lethality also occurred upon induction of ppGpp overaccumulation in E. coli. These data suggest that the precise regulation of ppGpp levels in the stressed cell is crucial, and that both the absence and the overaccumulation of ppGpp impair fatty acid starvation survival of light-exposed cells. Moreover, the UV-induced lethal effect during fatty acid starvation was also observed for $E$. coli strains mutated in rpos and dps, which, in the wild-type, are regulated directly or indirectly by ppGpp, respectively. The restoration of viability of fatty-acidstarved spoT mutant cells through the addition of exogenous catalase suggested that the observed light-dependent lethal effect was, at least in part, caused by UV-imposed oxidative stress. Based on these results, it is proposed that fatty acid starvation adaptation of light-exposed bacterial cells depends on the development of resistance to UV-induced oxidative stress. This stress resistance was found to require appropriate ppGpp levels, ppGpp-induced RpoS expression and, hence, upregulation of RpoS-regulated stress-defending genes, such as dps.

Keywords: fatty acid starvation, UV radiation

\section{INTRODUCTION}

Bacteria in natural environments are constantly challenged by nutrient limitation and stress conditions. Gram-negative, non-differentiating bacteria, such as Escherichia coli and 'Vibrio angustum' S14 (Vibrio sp. CCUG 15956; a model marine bacterium for studying starvation adaptation and stress responses), elicit soph-

Abbreviations: ppGppase, ppGpp hydrolase; PSI, ribosome-associated ppGpp synthetase; ROS, reactive oxygen species. isticated intracellular reorganization programmes in response to nutrient limitation, especially carbon starvation (Kjelleberg et al., 1993; Matin, 1991). Such programmes are characterized by a series of physiological and genetic changes that facilitate the development of multi-stress resistance, and which ultimately lead to long-term survival (Matin, 2000; Srinivasan \& Kjelleberg, 1998). Successful starvation adaptation requires many factors, including ppGpp (Cashel et al., 1996) and the stationary phase sigma factor $\sigma^{\mathrm{S}}$ (RpoS; Hengge-Aronis, 1996; Loewen \& Hengge-Aronis, 1994). 
ppGpp is an intracellular signal that accumulates in response to nutritional deficiency in prokaryotes, and its accumulation inhibits the synthesis of rRNA and proteins. The metabolism of ppGpp is mediated by two global regulatory proteins, RelA and SpoT (Cashel et al., 1996). RelA is a ribosome-associated ppGpp synthetase (PSI) that facilitates ppGpp accumulation upon amino acid deprivation. The SpoT protein is a bifunctional enzyme, incorporating a weak ppGpp synthetase (PSII) activity and a ppGpp hydrolase (ppGppase) activity. During carbon starvation, the ppGppase activity of SpoT is inhibited, leading to slow rates of ppGpp accumulation (Cashel, 2000). This spoT-dependent ppGpp accumulation occurs within the first few hours of carbon starvation (Flardh et al., 1994), and is essential for subsequent long-term survival (Nystrom, 1994). Furthermore, ppGpp accumulation activates the synthesis of RpoS in E. coli cells (Gentry et al., 1993; Lange et al., 1995), which in turn stimulates the expression of many stress-resistance genes (Loewen et al., 1998). For instance, the RpoS-regulated gene $d p s$ (encoding a DNAbinding protein during starvation) has been reported to be important in oxidative stress resistance (Almiron et al., 1992).

While the downstream events of the carbon starvation adaptive response are relatively well understood, little is known about how carbon starvation is sensed by a bacterium and linked to SpoT-mediated ppGpp accumulation and the consequent upregulation of RpoS (Matin, 2000). Studies of the cellular location of SpoT in E. coli have revealed that it is not associated with ribosomes and appears to be a cytosolic protein, which may monitor carbon source availability through a soluble signal molecule (Gentry \& Cashel, 1995). Through the use of mutants defective in the fatty acid synthesis pathway and cerulenin, a specific inhibitor of fatty acid synthesis (Omura, 1981), it has been found that fatty acid starvation in the presence of glucose and amino acids stimulates spoT-dependent ppGpp accumulation in E. coli (Seyfzadeh et al., 1993). The signalling pathway leading to this accumulation, and hence the inhibition of rRNA and protein synthesis, did not involve a significant decrease in the synthesis of either phospholipids or ATP. It may well be part of, or identical to, the still elusive SpoT-controlled carbon starvation response mechanism (Seyfzadeh et al., 1993). The precursor of fatty acid synthesis, acetyl CoA, is mainly produced during glycolysis when glucose is present as the sole carbon source. Therefore, glucose deprivation in bacteria apparently causes inhibition of fatty acid synthesis, leading to fatty acid starvation (DiRusso \& Nystrom, 1998). Following this rationale, it is possible that SpoT senses a signal generated during fatty acid metabolism to monitor carbon source availability during growth and carbon starvation (DiRusso \& Nystrom, 1998). Interestingly, ppGpp has a negative feedback effect on the fatty acid synthesis pathway, by inhibiting glycerol phosphate acyltransferase (Heath et al., 1994).

Fatty acid starvation can be mimicked through the addition of cerulenin, a polypeptide fungal mycotoxin, which binds tightly to two enzymes, 3-oxoacyl-[acylcarrier-protein] I and II synthases (encoded by $f a b B$ and $f a b F$, respectively). This binding prevents the catalysis of the elongation reaction, thus leading to the inhibition of both saturated and unsaturated fatty acid synthesis and hence growth arrest in bacteria (Moche et al., 1999). Fatty acid starvation halts synthesis of the bacterial lipid membrane, and continued growth of the bacteria results in lethal consequences. Hence, survival of fatty acid starvation depends critically on cessation of cell division and the reduction of growth and net protein synthesis through ppGpp accumulation, together with minimization of existing fatty acid turnover (DiRusso \& $\mathrm{Ny}-$ strom, 1998).

Previous studies in our laboratory have demonstrated that a ' $V$. angustum' S14 spoT mutant displays a severe loss in viability during carbon starvation (Ostling et al., 1995, 1996), a phenotype similar to that of the E. coli relA spoT mutant (Nystrom, 1994). Moreover, the carbon starvation lethality of the spoT mutant depends on laboratory fluorescent light, which emits extremely weak UV radiation (Ostling et al., 1995). However, ppGpp levels are increased in the carbon-starved ' $V$. angustum' S14 spoT mutant in contrast to the E. coli relA spoT mutant, which displays decreased levels of ppGpp (Ostling et al., 1995; Xiao et al., 1991). To further address the above postulated link between carbon starvation and fatty acid starvation, two important factors in carbon starvation survival, spoTdependent ppGpp accumulation and the RpoS regulon, were examined during cerulenin-induced fatty acid starvation. Furthermore, these factors were characterized with regard to their roles in starvation-induced stress resistance. Through the use of various mutant strains of E. coli and ' $V$. angustum' S14, we report that SpoT-mediated ppGpp accumulation, RpoS and the RpoS-controlled DNA-binding protein (Dps) are required for fatty acid starvation survival in the presence of cool-white fluorescent light. This survival is partly dependent on the resistance to oxidative stress imposed by the weak UV radiation from laboratory fluorescent light. The possible negative effect of ppGpp overaccumulation on fatty acid starvation survival is also discussed.

\section{METHODS}

Bacterial strains and plasmids. The bacterial strains and plasmids used in this study are listed in Table 1. Marine ' $V$. angustum' S14 (CCUG 15956) strains S141, KF21 and J109 have been described previously (Albertson et al., 1990; Flardh et al., 1994; Marden et al., 1987; Ostling et al., 1991, 1995). E. coli strains MG1655, CF1652, CF1693, CF5747, CF5748, CF4941 and CF4943 were obtained from Michael Cashel (Laboratory of Molecular Genetics, NICHD, National Institutes of Health, USA). E. coli strains ZK126, ZK1000 and ZK1058 were gifts from Roberto Kolter (Department of Microbiology and Molecular Genetics, Harvard Medical School, USA). The plasmid pALS13 (Svitil et al., 1993), carrying a $\mathrm{P}_{l a c}$-controlled truncated relA gene encoding a 455 aa RelA peptide with PSI activity, was propagated in strain 
Table 1. Bacterial strains and plasmids used in this study

\begin{tabular}{|c|c|c|}
\hline Strain/plasmid & Relevant characteristics* & Reference \\
\hline \multicolumn{3}{|l|}{ E. coli } \\
\hline MG1655 & $\lambda^{-} \mathrm{F}^{-}$ & Bachmann \& Low (1984) \\
\hline CF1652 & MG1655 $\Delta$ relA251::kan & Xiao et al. (1991) \\
\hline CF1693 & 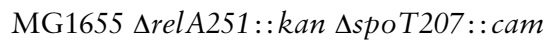 & Xiao et al. (1991) \\
\hline ZK126 & W3110 tna-2 lacU169 & Connell et al. (1987) \\
\hline ZK1000 & ZK126 rpos::kan & Bohannon et al. (1991) \\
\hline ZK1058 & ZK126 dps::kan & Almiron et al. (1992) \\
\hline CF4941 & MG1655 zib563::Tn10, srelA251::kan & Gentry et al. (1993) \\
\hline CF4943 & CF4941 spoT203 & Gentry et al. (1993) \\
\hline CF5747 & MG1655 pALS13 & Svitil et al. (1993) \\
\hline CF5748 & MG1655 pALS14 & Svitil et al. (1993) \\
\hline \multicolumn{3}{|c|}{ 'V. angustum' S14 } \\
\hline S141 & $\mathrm{S} 14, \mathrm{Sm}^{\mathrm{r}}$ & Ostling et al. (1991) \\
\hline KF21 & $\mathrm{S} 141, \Delta \operatorname{relA}:$ :kan & Flardh et al. (1994) \\
\hline J109 & $\mathrm{S} 141$, spoT::kan & Ostling et al. (1995) \\
\hline \multicolumn{3}{|l|}{ Plasmids } \\
\hline pALS13 & $\mathrm{Ap}^{\mathrm{r}}, \mathrm{P}_{l a c}:$ :relA (1-455 aа) & Svitil et al. (1993) \\
\hline pALS14 & $\mathrm{Ap}^{\mathrm{r}}, \mathrm{P}_{l a c}:$ :relA (1-331 aa) & Svitil et al. (1993) \\
\hline
\end{tabular}

*Ap ${ }^{\mathrm{r}}$, Ampicillin resistance; $\mathrm{Sm}^{\mathrm{r}}$, streptomycin resistance; $\mathrm{P}_{l a c}$, E. coli lac operon promoter.

MG1655, to give strain CF5747. The plasmid pALS14 (Svitil et al., 1993), carrying a $\mathrm{P}_{l a c}$-controlled controlled truncated relA gene encoding a 331 aa RelA peptide without PSI activity, was propagated in strain MG1655, to give strain CF5748.

Media and growth conditions. E. coli strains were grown at $30{ }^{\circ} \mathrm{C}$ on Luria-Bertani (LB) agar (Sambrook et al., 1989). ' $V$. angustum' S14 strains were grown at $26^{\circ} \mathrm{C}$ on VNSS agar (Marden et al., 1985). For liquid cultures of E. coli strains, culture side-arm flasks were inoculated with freshly grown colonies and grown at $30^{\circ} \mathrm{C}$ on a rotary shaker (160 r.p.m.) in MOPS medium supplemented with $0 \cdot 2 \%$ glucose, $10 \mu \mathrm{g}$ thiamin $\mathrm{ml}^{-1}, 40 \mu \mathrm{g}$ uridine $\mathrm{ml}^{-1}$ and $0 \cdot 1 \%$ Casamino acids (Neidhardt et al., 1974). For liquid cultures of ' $V$. angustum' S14 strains, culture side-arm flasks were inoculated with freshly grown colonies and grown at $26{ }^{\circ} \mathrm{C}$ on a rotary shaker (160 r.p.m.) in marine minimal medium (MMM) supplemented with $0 \cdot 2 \%$ glucose, $10 \mu \mathrm{g}$ thiamin $\mathrm{ml}^{-1}, 40 \mu \mathrm{g}$ uridine $\mathrm{ml}^{-1}$ and $0 \cdot 1 \%$ Casamino acids (Ostling et al., 1991). Growth was monitored as a function of optical density measured at $600 \mathrm{~nm}\left(\mathrm{OD}_{600}\right)$ with a Pharmacia LKB Novaspec II spectrophotometer. Where appropriate, antibiotics were used at the following concentrations: $100 \mu \mathrm{g}$ ampicillin $\mathrm{ml}^{-1} ; 12 \cdot 5 \mu \mathrm{g}$ tetracycline $\mathrm{ml}^{-1} ; 50 \mu \mathrm{g}$ kanamycin $\mathrm{ml}^{-1}$ for E. coli strains and $85 \mu \mathrm{g} \mathrm{ml}^{-1}$ for ' $V$. angustum' S14 strains; $50 \mu \mathrm{g}$ chloramphenicol $\mathrm{ml}^{-1}$; and $200 \mu \mathrm{g}$ streptomycin $\mathrm{ml}^{-1}$.

Starvation conditions and light source. Fatty acid starvation was achieved by adding cerulenin (Sigma) to a final concentration of $200 \mu \mathrm{g} \mathrm{ml}^{-1}$ to cultures at $\mathrm{OD}_{600} 0 \cdot 2$. Cultures subjected to starvation regimens were stored statically in glass flasks positioned on the laboratory bench top, either directly under the light of a cool-white fluorescent lamp (F15T8CW, Philips Lighting) or under the light covered by a sheet of UVcutoff perspex (GE Lexan XL-10, Cadillac). The distance between the lamp and the flasks was $50 \mathrm{~cm}$. According to the information provided by the manufacturer, the UV emission spectrum of the light source was mainly identical in the UVA
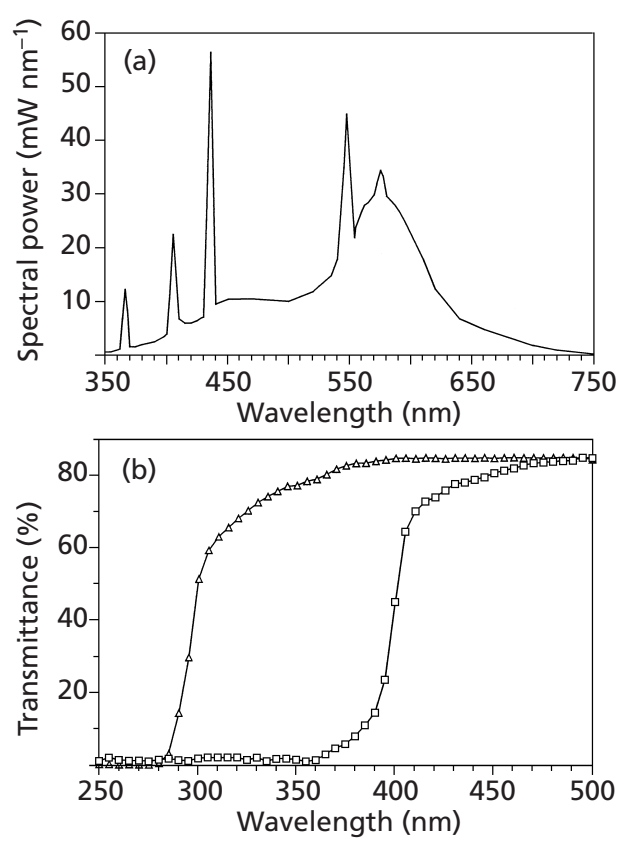

Fig. 1. Spectrum of the cool-white fluorescent lamp used in this study (a) and UV-visible light transmission of the perspex ( $\square$ ) and the glass flask $(\triangle)$ used in this study (b).

$(320-400 \mathrm{~nm})$ region with a peak at $366 \mathrm{~nm}$ (Fig. 1a). The intensities of UVB $(290-320 \mathrm{~nm})$ and UVC ( $<290 \mathrm{~nm})$ light were much lower than that of the UVA in the cool-white fluorescent light (Cebula et al., 1995). The perspex sheet and the glass flask used in this study were placed into the beam of a visible-UV spectrophotometer (DU640, Beckman), and their 
UV-visible light transmittance spectra in the $250-500 \mathrm{~nm}$ range were obtained (Fig. 1b). The perspex sheet was essentially opaque at all wavelengths below $400 \mathrm{~nm}$ (UVA, UVB and UVC). The glass flask was opaque to UV wavelengths of $290 \mathrm{~nm}$ or less (UVC). Measured by a wavelength UV-meter (UV products) outside the glass flasks, the mean fluence rate used for the cool-white fluorescent light exposure in this study was $0.2 \mathrm{~W} \mathrm{~m}$. In all experiments, nonilluminated flasks covered with aluminium foil were used as controls. Restoration experiments were performed with illuminated starvation-stressed cells, to which $26 \mathrm{U}_{\text {catalase } \mathrm{ml}^{-1}}$ (Sigma) was added at $0 \mathrm{~h}$ of starvation. Viability was assessed at appropriate time intervals in terms of c.f.u. $\mathrm{ml}^{-1}$ on appropriate agar plates, by the drop-plate method (Hoben \& Somsegaran, 1982).

Measurement of the rates of total RNA synthesis. The rate of total RNA synthesis was determined as the rate of pulselabelled radioactive uridine incorporation into trichloroacetic acid (TCA)-insoluble material (Flardh et al., 1992). Aliquots of an experimental culture were labelled with $0 \cdot 13 \mathrm{mM}[5,6-$ ${ }^{3} \mathrm{H}$ ] uridine [37.8 $\mathrm{Ci} \mathrm{mmol}^{-1}\left(1.4 \mathrm{TBq} \mathrm{mmol}^{-1}\right)$, Amersham]. At appropriate intervals, $50 \mu \mathrm{l}$ of the culture was removed and added to $800 \mu \mathrm{l}$ ice-cold $10 \%$ TCA; the resulting preparations were kept on ice for $1 \mathrm{~h}$ prior to collection of the precipitated material on polycarbonate membrane filters (pore size $0.2 \mu \mathrm{m}$, Millipore). The precipitates were washed three times with icecold 5\% TCA and then transferred to scintillation vials (Crown Scientific). Opti-Phase 'Hi-Safe'3 (Fisher Chemicals) was used as the scintillation cocktail, and the radioactivity was determined with a Packard series 20000 liquid scintillation counter. The rates of uridine incorporation were determined from the slopes of the linear incorporation graphs (Nystrom et al., 1986).

Measurement of ppGpp. The method used to assay ppGpp was performed as described by Cashel (1994). Briefly, cells were grown in the appropriate minimal medium with a low phosphate concentration $(0.4 \mathrm{mM})$. When $\mathrm{OD}_{600} 0.05$ was reached, $\left[{ }^{32} \mathrm{P}\right]$ orthophosphate (Amersham) was added to a culture aliquot at a concentration of $100 \mu \mathrm{Ci} \mathrm{ml}^{-1}$, and incubation was continued for about $120 \mathrm{~min}$. Cell densities were monitored in an unlabelled culture aliquot. Sampling for ppGpp began at $\mathrm{OD}_{600} 0 \cdot 2-0 \cdot 5$. The samples were then mixed with $13 \mathrm{M}$ formic acid and three freeze-thaw cycles were performed. Afterwards, the samples were centrifuged and $5 \mu \mathrm{l}$ samples of supernatant were subjected to one-dimensional TLC on polyethyleneimine sheets (Merck) and developed with $1.5 \mathrm{M}$ potassium phosphate $(\mathrm{pH} 3.4)$. Nucleotide abundance was quantified by a Phosphor-Imager Analysis System (Bio$\mathrm{Rad})$. Amounts of ppGpp were expressed as the total activity (c.p.m.) of blank-corrected ppGpp per $\mathrm{OD}_{600}$ unit of culture.

\section{RESULTS}

\section{Light-exposed ' $V$. angustum' S14 spoT and E. coli relA spoT mutants display severe losses in viability during fatty acid starvation}

It has previously been found that fatty acid starvation, induced by the addition of cerulenin in the presence of glucose and amino acids, stimulates spoT-dependent ppGpp accumulation in E. coli (Seyfzadeh et al., 1993). To further investigate the consequences of this ppGpp accumulation in response to fatty acid starvation in bacteria, the survival abilities of $E$. coli and ' $V$. angustum' S14 relA mutants and spoT mutants were compared to those of their respective isogenic wild-type strains during fatty acid starvation (Fig. 2). After $55 \mathrm{~h}$ fatty acid starvation under cool-white fluorescent light, both the ' $V$. angustum' S14 spoT mutant and the E. coli relA spo $T$ mutant displayed a pronounced loss in viability ( 6.6 and $4.1 \mathrm{log}$, respectively) in comparison to the wild-type strains and the relA mutants (Fig. 2). Interestingly, these data also demonstrated that ' $V$. angustum' S14 strains are more sensitive to fatty acid starvation than E. coli strains (Fig. 2). When the same starvation experiments were performed in complete darkness, much smaller losses in viability were observed, for all strains tested, in comparison to those exposed to light (Fig. 2). When the same starvation experiments were performed under the fluorescent light filtered by a UV-resistant perspex sheet, only minor losses in viability were observed for all strains (data not shown), which were similar to those observed in the dark (Fig. 2). These results demonstrate that the spoT, but not the relA mutations, in ' $V$. angustum' S14 and E. coli exacerbate the decline in viability during fatty acid starvation in the light. This spoT-dependent increased rate of loss in viability is dependent on the UV emission from the normal cool-white fluorescent lamp. In this experiment, no significant loss in viability was observed in all strains tested under the control conditions (without fatty acid starvation in the light and dark) within $55 \mathrm{~h}$ (data not shown). These results specifically relate the lethal effect of light on the spoT mutants to fatty acid starvation, as opposed to any implication of lethality due solely to light exposure. After $5 \mathrm{~d}$ treatment in the light or dark, nearly all of the fatty-acid-starved cells of the tested strains were dead, whereas the non-starved cells maintained viability (data not shown), confirming the final lethal consequences of fatty acid starvation.

\section{The ' $V$. angustum' S14 spoT mutant displays high ppGpp levels during fatty acid starvation}

While both the ' $V$. angustum' $\mathrm{S} 14$ spoT mutant and the E. coli relA spoT mutant exhibited light-dependent fatty acid starvation lethality, the alterations in their respective ppGpp levels were distinct during fatty acid starvation (Fig. 3). Wild-type E. coli and 'V. angustum' S14 displayed an initial increase in ppGpp levels upon fatty acid starvation in the presence of glucose and amino acids, followed by a gradual decrease in the ppGpp levels after $1 \mathrm{~h}$ starvation (Fig. 3). The " $V$. angustum' S14 spoT strain J109 displayed a threefold higher level of ppGpp in comparison to that of the isogenic wild-type strain $\mathrm{S} 141$ after $1 \mathrm{~h}$ fatty acid starvation, whereas the E. coli ppGpp ${ }^{0}$ strain CF1693 did not display ppGpp accumulation during fatty acid starvation (Fig. 3). In contrast, the relA mutants displayed the same alterations in ppGpp levels as those of the wild-type strains (Fig. 3). The higher ppGpp level observed in the ' $V$. angustum' S14 spoT mutant during fatty acid starvation is similar to that observed during carbon starvation (Ostling et al., 1995). Furthermore, an inverse correlation was observed between ppGpp levels and the synthesis rates of stable RNA during the fatty 

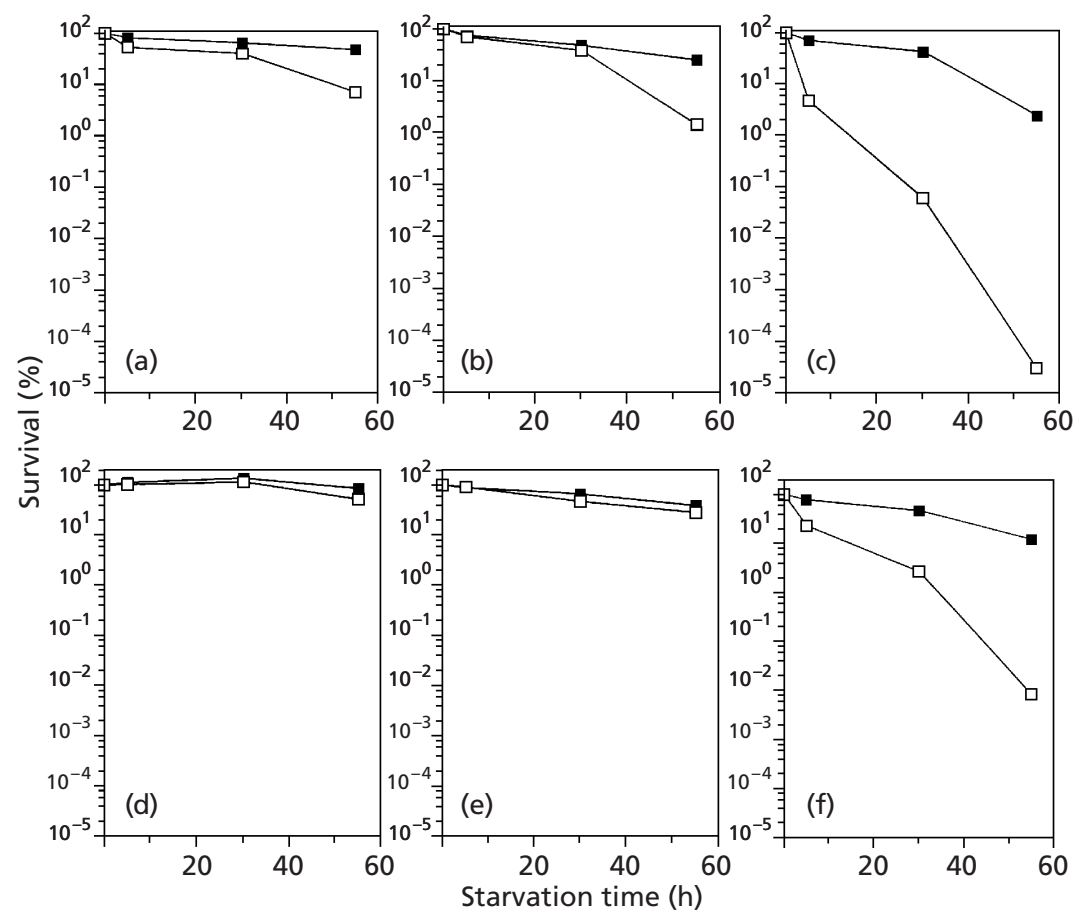

Fig. 2. Survival of ' $V$. angustum' $S 14$ strains and $E$. coli strains under cool white fluorescent light $(\square)$ or in complete darkness (ם) during fatty acid starvation. (a) Wildtype ' $V$. angustum' S141, (b) ' $V$. angustum' S14 relA mutant KF21, (c) ' $V$. angustum' S14 spoT mutant J109, (d) E. coli wild-type MG1655, (e) E. coli relA mutant CF1652, and (f) E. coli relA spoT mutant CF1693. Incubation was continued for $55 \mathrm{~h}$ subsequent to growth arrest when the c.f.u. counts were approximately $10^{8}$ cells $\mathrm{ml}^{-1}$ (see Methods for details). Representative data from one of three replicate experiments are shown.

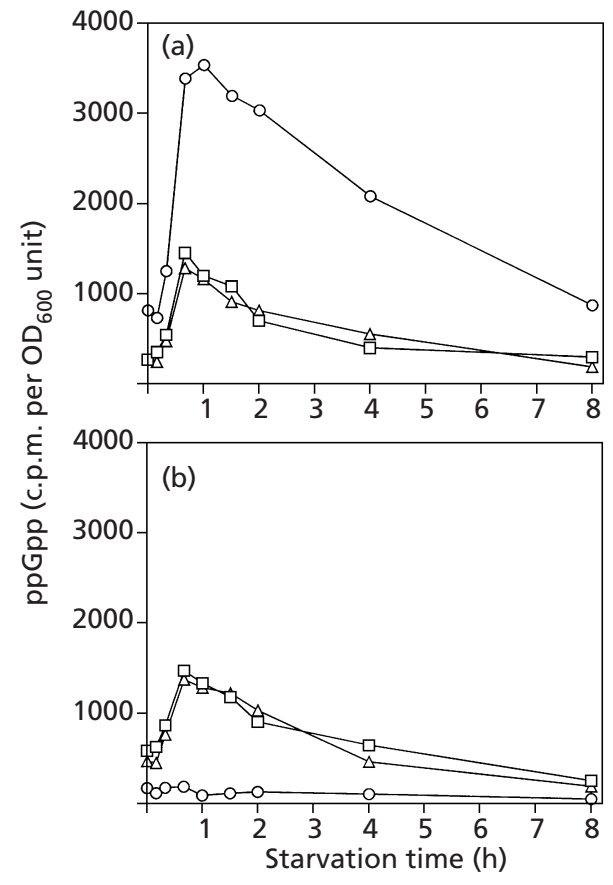

Fig. 3. Alterations in the ppGpp levels during fatty acid starvation under light in strains of ' $V$. angustum' S14 and $E$. coli. (a) $\square$, ' $V$. angustum' $S 141$ wild-type; $\triangle$, 'V. angustum' KF21 ( $\Delta$ relA::kan); O, 'V. angustum' J109 (spoT::kan). (b) $\square$, E. coli MG1655 wild-type; $\triangle$, E. coli CF1652 ( $\Delta$ relA::kan); O, $E$. coli CF1693 ( $\Delta$ relA::kan $\Delta$ spoT::cam). Cellular ppGpp was labelled with [ $\left.{ }^{32} \mathrm{P}\right]$ orthophosphate, extracted and quantified as c.p.m. per $\mathrm{OD}_{600}$ unit by TLC. See Methods for details. Representative data from one of three replicate experiments are shown. acid starvation conditions described above (data not shown), corroborating previous reports that have demonstrated RNA synthesis rate measurements to reflect variation in ppGpp levels (Cashel et al., 1996).

\section{Overaccumulation of ppGpp in E. coli causes fatty acid starvation lethality for light-exposed cells}

The fatty acid starvation lethality of the E. coli ppGpp ${ }^{0}$ strain CF1693 demonstrated that ppGpp is required for survival under light. On the other hand, the higher ppGpp levels and the severe loss in viability of the ' $V$. angustum' S14 spoT mutant during fatty acid starvation implied that overaccumulation of ppGpp also impairs successful resistance. To further investigate this hypothesis, E. coli RelA overexpression strains CF5747 and CF5748 (Svitil et al., 1993) were assayed for fatty acid starvation survival during light exposure. IPTGinduced RelA overexpression in strain CF5747 elicited ppGpp overaccumulation: a 20 -fold increase in the ppGpp levels of the IPTG-treated cells in comparison to a threefold increase in the untreated cells was observed after $1 \mathrm{~h}$ fatty acid starvation (Fig. 4a). This overaccumulation of ppGpp reduced the synthesis rates of total RNA (data not shown) and impaired the ability of the cells to survive fatty acid starvation in the light. A $3 \cdot 2 \mathrm{log}$ drop in the c.f.u. count of the IPTG-treated cells in comparison to a $0 \cdot 2 \log$ drop in the c.f.u. count of the untreated cells after $40 \mathrm{~h}$ fatty acid starvation was observed (Fig. 4b). In contrast, the overexpression of an inactive 331 aa RelA peptide in strain CF5748 (Svitil et al., 1993) had no such effect (data not shown). The 455 aa truncated RelA peptide expressed in strain CF5747 is 

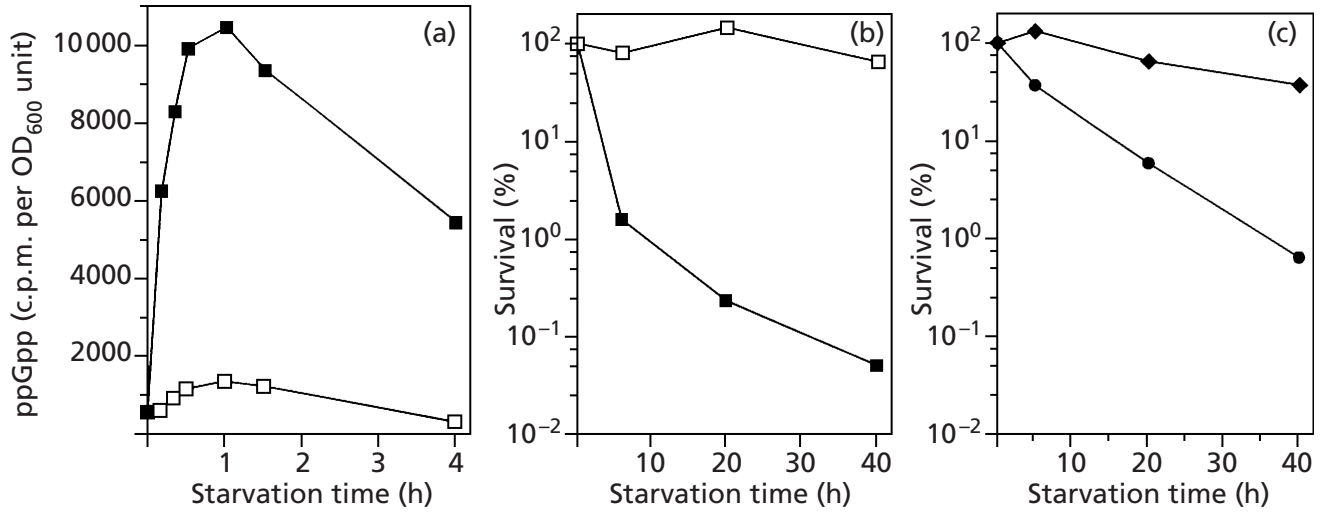

Fig. 4. (a, b) Effect of RelA overexpression on the ppGpp accumulation (a) and the survival ability (b) of $E$. coli strain CF5747 during fatty acid starvation under light. RelA was induced by adding 1 mM IPTG to E. coli strain CF5747 carrying $P_{\text {lac }}:$ :relA on plasmid pALS13 (Svitil et al., 1993). $\square$, $\mathbf{a}$ denote the data for cells without and with IPTG, respectively. (c)

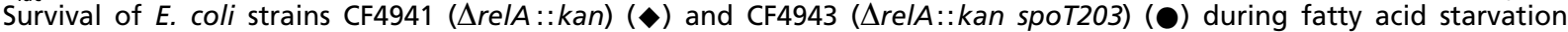
under light. Further details are described in Results and Discussion. Representative data from one of two replicate experiments are shown.

metabolically unstable, which avoids the toxic effect of protein overexpression (Svitil et al., 1993). Taking strain CF5748 as a negative control, the data suggest that the light-dependent fatty acid starvation lethality of strain CF5747 may be due to ppGpp overaccumulation, rather than to the toxic effects of protein overexpression, plasmid maintenance, or IPTG itself. Moreover, the artificial overproduction of ppGpp resulted in reduced lethality in strain CF5747 in the absence of starvation, as well as during starvation in the dark (data not shown). In E. coli, the spoT203 allele has been found to reduce ppGpp degradative activity, resulting in an eightfold elevation of ppGpp levels (Sarubbi et al., 1988). During fatty acid starvation under light exposure, E. coli CF4943, containing the spoT203 mutation, displayed a significant decline in viability in comparison to its isogenic parent strain, CF4941 (Fig. 4c). These results support our hypothesis that overaccumulation of ppGpp impairs the survival ability of the illuminated fatty-acidstarved cells.

\section{Light-exposed E. coli strains with mutations in rpoS and $d p s$ display severe losses in viability during fatty acid starvation}

It has been found that ppGpp upregulates the synthesis of the stationary-phase sigma factor RpoS in E. coli (Gentry et al., 1993; Lange et al., 1995). RpoS and RpoSregulated proteins (e.g. Dps) are crucial for starvationinduced stress resistance and starvation survival (Almiron et al., 1992; Eisenstark et al., 1996; HenggeAronis, 1996; McCann et al., 1991). To investigate the role of the RpoS regulon in fatty acid starvation, rpoS and $d p s$ mutant $E$. coli strains were compared in survival ability to the isogenic wild-type strain during fatty acid starvation (Fig. 5). After $55 \mathrm{~h}$ fatty acid starvation under cool-white fluorescent light, both mutants displayed significantly greater losses in viability in comparison to the wild-type strain. The rpoS mutant exhibited a $2 \cdot 9 \log$ decrease in viability, whereas the corresponding values for the $d p s$ mutant and the wild-type strain were $5 \cdot 6 \mathrm{log}$ and $0.5 \mathrm{log}$, respectively (Fig. 5). When these starvation experiments were performed in complete darkness, much smaller losses in viability were observed for all strains tested in comparison to those kept in the light (Fig. 5). When these starvation experiments were performed under the fluorescent light filtered through a UVresistant perspex sheet, the minor losses in viability, for all strains, were identical to those observed in the dark (data not shown). These data indicated that $r p o S$ and the RpoS-regulated stress-resistance gene $d p s$ are involved in fatty acid starvation survival during light exposure. The main challenge to the cells under these conditions appears to be the UV radiation from the coolwhite fluorescent lamp used. Moreover, the difference between the losses in viability of the rpoS and $d p s$ mutants during fatty acid starvation suggests a potential direct role for DNA-binding protein in starvation (Dps) in fatty acid starvation survival under light.

\section{Addition of catalase to the illuminated culture largely restores viability of ' $V$. angustum' S14 and $E$. coli spoT mutants during fatty acid starvation}

The main fraction of the UV emission from the coolwhite fluorescent light is UVA radiation (Cebula et al., 1995), which causes oxidative damage to DNA and proteins in bacteria through photo-oxidation (Eisenstark, 1989). Therefore, the light-dependent lethality of the spo $T$ mutants during fatty acid starvation is likely to be related to the UV-induced oxidative stress. To address the role of oxidative stress resistance in the fatty acid starvation response, we investigated the effect of catalase, an $\mathrm{H}_{2} \mathrm{O}_{2}$-degrading enzyme, on the survival of the fatty-acid-starved E. coli and ' $V$. angustum' S14 cells. Addition of catalase resulted in an increase in viability for illuminated spoT mutant cultures of ' $V$. angustum' S14 and E. coli that were fatty acid starved for $35 \mathrm{~h}$, in 

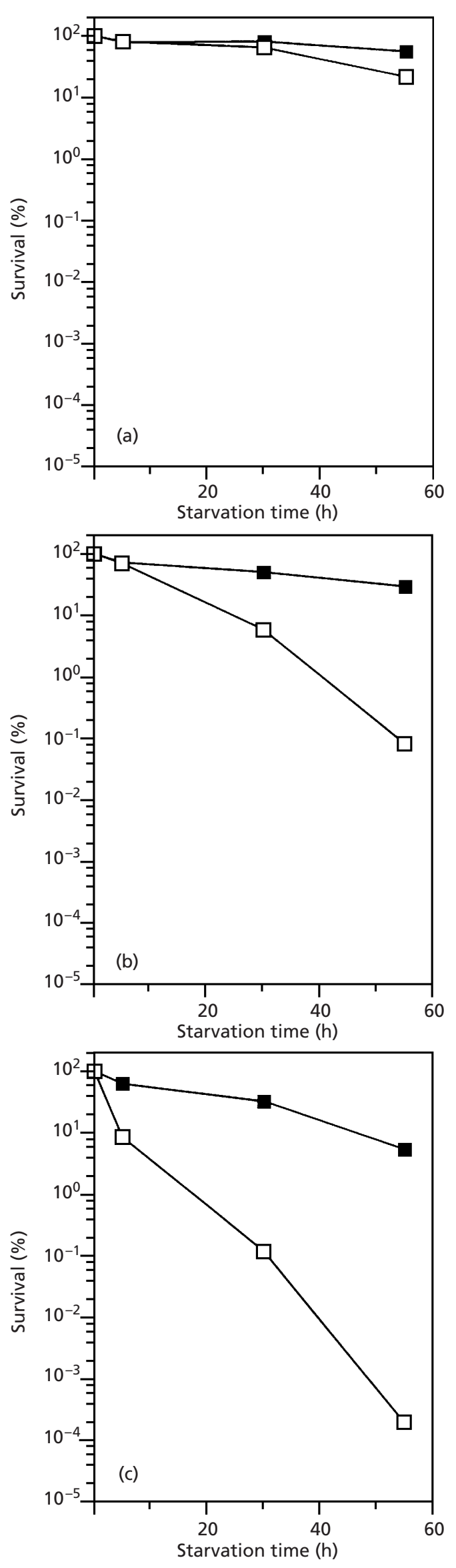

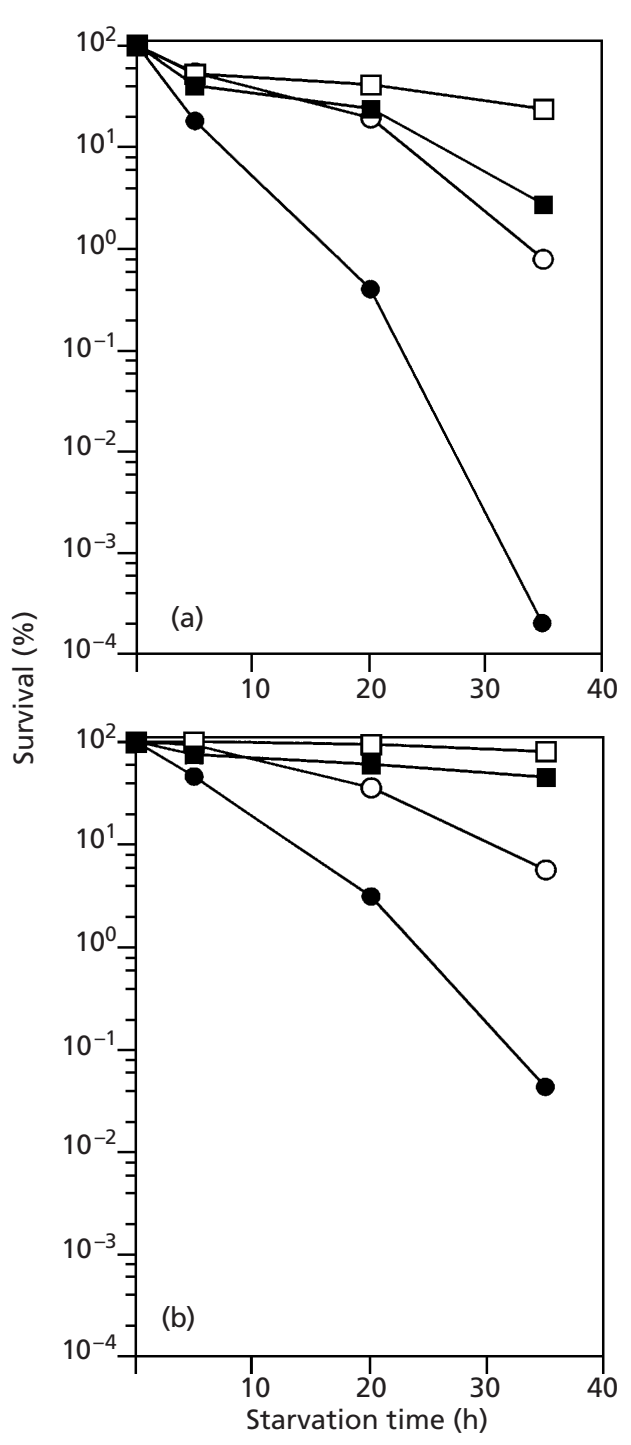

Fig. 6. Effect of catalase on the survival of illuminated fatty acid starved cells of ' $V$. angustum' $\mathrm{S} 14$ and $E$. coli. (a) ' $V$. angustum' S141 wild-type (squares) and ' $V$. angustum' J109 (spoT::kan) (circles). (b) E. coli MG1655 wild-type (squares) and E. coli CF1693 ( $\Delta$ relA::kan $\Delta$ spoT::cam) (circles). Experiments were performed with illuminated fatty-acid-starved cells in non-supplemented medium (solid symbols) or medium supplemented with catalase (open symbols). Representative data from one of three replicate experiments are shown.

comparison to non-catalase-supplemented cells (Fig. 6). Specifically, the ' $V$. angustum' S14 spoT mutant displayed an increase in viability of three orders of magnitude (Fig. 6a), whereas the E. coli relA spoT

Fig. 5. Survival of $E$. coli strains during fatty acid starvation under cool-white fluorescent light $(\square)$ or in complete darkness (ם). (a) E. coli ZK126 wild-type; (b) E. coli rpoS mutant ZK1000; (c) E. coli dps mutant ZK1058. Incubation was continued for $55 \mathrm{~h}$ subsequent to growth arrest when the c.f.u. counts were approximately $10^{8}$ cells ml ${ }^{-1}$ (see Methods for details). Representative data from one of three replicate experiments are shown. 
mutant displayed an increase of two orders of magnitude (Fig. 6b) upon the addition of catalase. The c.f.u. counts of the ' $V$. angustum' S14 and E. coli wild-type strains were also increased slightly by catalase addition after $35 \mathrm{~h}$ of starvation (Fig. 6), indicating that catalase has a general effect on the fatty acid starvation survival of the illuminated cells. These results suggest that the UVimposed oxidative stress accounts for the severe decline in viability of the fatty-acid-starved spoT mutant cells.

\section{DISCUSSION}

It has been reported that fatty acid starvation in the presence of glucose and amino acids stimulates a spoTdependent ppGpp accumulation in E. coli (Seyfzadeh et al., 1993). The present report demonstrates that a ' $V$. angustum' S14 spoT mutant and an E. coli relA spoT mutant display severe losses in viability in response to cerulenin-induced fatty acid starvation under cool-white fluorescent light in the presence of glucose and amino acids (Table 2). In contrast, the respective relA mutants and wild-type strains exhibited little or no loss in viability under the same conditions. On the other hand, the mutant cells starved in the dark or under the light filtered by a UV-cutoff perspex sheet did not display this pronounced loss in viability. Therefore, the spoTdependent increased rate of decline in cell viability during fatty acid starvation is provoked by fluorescent light illumination, in particular the weak UV emission from the light used. This light-dependent lethal effect during fatty acid starvation also occurred in the E. coli strains with mutations in $r p o S$ and $d p s$ (Table 2).

\section{Role of SpoT during carbon and fatty acid starvation}

We propose that SpoT senses a signal generated in fatty acid metabolism to monitor carbon source availability during growth, and during carbon starvation. The SpoT-mediated ppGpp accumulation (Seyfzadeh et al., 1993) and the spoT-dependent survival during fatty acid starvation are similar to the characteristics of the carbon-starved cells (Flardh et al., 1994; Nystrom, 1994; Ostling et al., 1995; Xiao et al., 1991). These data suggest that the signalling pathway leading to ppGpp accumulation upon fatty acid starvation may be part of, or identical to, the as yet elusive SpoT-controlled carbon starvation response mechanism (Seyfzadeh et al., 1993). Consistent with this idea, it was found that carbonstarved E. coli cells with a mutation in accD (a gene encoding acetyl-CoA carboxylase, a key enzyme in fatty acid biosynthesis) display an aberrant pattern of ppGpp accumulation, excessive cell division, and progressive failure to respond rapidly to a nutritional up-shift (Seyfzadeh, 1994). It is well known that the precursor of fatty acid synthesis, acetyl-CoA, is mainly produced during glycolysis when glucose acts as the sole carbon source. Therefore, glucose deprivation in bacteria apparently causes inhibition of fatty acid synthesis, leading to fatty acid starvation (DiRusso \& Nystrom, 1998). Following this rationale, it is possible that SpoT normally responds to a signal produced in fatty acid metabolism to monitor carbon source abundance, and optimizes growth economy of the cell accordingly (DiRusso \& Nystrom, 1998; Gentry \& Cashel, 1995). This putative signal may be synthesized from fatty acid derivatives, such as fatty acyl-CoA, and inhibit the SpoT

Table 2. Relative viability of the strains in fatty acid starvation

When catalase was present it was added at $26 \mathrm{U} \mathrm{ml}^{-1}$. All strains exhibited no differences during growth in light vs growth in dark.

\begin{tabular}{|c|c|c|}
\hline \multirow[t]{2}{*}{ Strain } & \multicolumn{2}{|c|}{ Fatty acid starvation" } \\
\hline & Light & Dark \\
\hline 'V. angustum' S14 wild-type & ++ & +++ \\
\hline ' $V$. angustum' S14 wild-type + catalase & +++ & +++ \\
\hline ' $V$. angustum' S14 relA mutant & + & ++ \\
\hline 'V. angustum' S14 spoT mutant & --- & + \\
\hline ' $V$. angustum' S14 spoT mutant + catalase & + & ++ \\
\hline E. coli wild-type & +++ & +++ \\
\hline E. coli wild-type + catalase & +++ & +++ \\
\hline E. coli relA mutant & ++ & ++ \\
\hline E. coli relA spoT mutant & -- & ++ \\
\hline E. coli relA spoT mutant + catalase & ++ & +++ \\
\hline E. coli rpoS mutant & - & ++ \\
\hline E. coli $d p s$ mutant & --- & + \\
\hline E. coli wild-type $\mathrm{P}_{l a c}$ : :relA & +++ & +++ \\
\hline E. coli wild-type $\mathrm{P}_{l a c}:: r e l A+1 \mathrm{mM}$ IPTG & -- & + \\
\hline
\end{tabular}

$*+++,<0 \cdot 2 \log \operatorname{loss} ;++, 0 \cdot 5-1 \log \operatorname{loss} ;+, 1-2 \log \operatorname{loss} ;-, 2-3 \log \operatorname{loss} ;--, 3-4 \log \operatorname{loss} ;$ ,$--->4 \log \operatorname{loss}$. 
function responsible for ppGpp accumulation and further starvation survival, perhaps by directly binding to the SpoT protein or by binding to another positive factor required for SpoT function (Seyfzadeh et al., 1993). Hence, fatty acid starvation leads to the loss of this signal and upregulation of SpoT-mediated ppGpp accumulation. Alternatively, carbon starvation and fatty acid starvation may use independent signal transduction mechanisms to trigger spoT-dependent ppGpp accumulation and further starvation adaptive responses. Further studies of the signalling pathway(s) leading to ppGpp accumulation during fatty acid starvation are currently being undertaken.

\section{UV-induced oxidative stress and fatty acid starvation}

It is interesting that the fatty acid starvation lethality of the cells with mutations in spoT, rpoS and $d p s$ is provoked by standard laboratory cool-white fluorescent light. Furthermore, this lethal effect was found to be mostly due to the weak UV emission of the light. According to the information provided by the manufacturer, the main fraction of the UV emission from the cool-white fluorescent lamp is UVA radiation (Fig. 1a). The lamp also emits very low levels of UVB and UVC that may cause direct damage to DNA (Cebula et al., 1995). However, the effect of UVC can be ruled out in this study since the glass flasks we used block UVC radiation (Fig. 1b). UVA and UVB produce many reactive oxygen species (ROS) through photo-oxidation and hence cause oxidative damage to DNA, proteins and membrane lipids in bacteria (Eisenstark, 1989). ROS are produced during normal cellular metabolism, but can be augmented after cellular exposure to UV, especially in the presence of various photo-sensitizers (Jagger, 1981). The light-dependent lethal effects reported here are suggested to be mainly due to UVinduced oxidative stress rather than to direct DNA damage. This hypothesis was also supported by the following findings: (i) the spoT mutants were found to be more sensitive to UV radiation as well as to $\mathrm{H}_{2} \mathrm{O}_{2}$ exposure in comparison to their isogenic parents during fatty acid starvation (unpublished data); (ii) addition of exogenous catalase to the growth medium during fatty acid starvation in this study reversed most of the loss in cell viability of the spoT mutants provoked by fluorescent light illumination (Fig. 6). We note that since only UVA and UVB of solar UV irradiation reach marine surface waters, the natural habitats of marine Vibrio species, our findings have clear ecological implications (Joux et al., 1999). Moreover, our observed lethal effects occur in starved cells exposed to extremely weak UV radiation from laboratory cool-white fluorescent light. Its intensity $\left(0.2 \mathrm{~W} \mathrm{~m}^{-2}\right)$ is much lower than that of full sunlight $\left(33 \mathrm{~W} \mathrm{~m}^{-2}\right)$, and is typical of the intensities found in marine surface waters, where the UV radiation is quenched (Jeffrey et al., 1996).

One of the factors that appear to play an important role in the response of bacterial cells to UV irradiation is the mechanism known as stringent response. It is well known that UV exposure affects tRNA containing a 4- thiouridine modified base, which cross-links with cytidine, losing its charge capacity and triggering the stringent response with RelA-mediated ppGpp accumulation and the consequent arrest of rRNA and protein biosynthesis. This mechanism induces a growth delay, including impairment of replication and membrane integrity in E. coli (Jagger, 1981; Thiam \& Favre, 1984), Salmonella typhimurium (Kramer et al., 1988) and Pseudomonas aeruginosa (Fernandez \& Pizarro, 1999). It may be questioned whether the UV emission employed in this study, rather than fatty acid starvation, provoke the ppGpp accumulation observed in this study. However, our experimental conditions are distinct from the UV radiation used in the studies reported above. Firstly, the fluence rate of UV emission used here is $0.2 \mathrm{~W} \mathrm{~m}^{-2}$, which is much lower than the levels reported before: $216 \mathrm{~W} \mathrm{~m}^{-2}$ for E. coli (Jagger, 1981; Thiam \& Favre, 1984), and $35 \mathrm{~W} \mathrm{~m}^{-2}$ for S. typhimurium (Kramer et al., 1988 ) and P. aeruginosa (Fernandez \& Pizarro, 1999). Secondly, in contrast to the findings reported in the papers cited above, we did not observe growth delay or significant ppGpp accumulation in the growing cells illuminated by the cool-white fluorescent light (data not shown). Thirdly, the patterns of ppGpp accumulation we observed for the fatty-acid-starved cells in the light and dark are similar (data not shown), suggesting that starvation, instead of light, is needed as a means of inducing ppGpp. It is therefore suggested that the extremely weak UV emission used in this study do not serve as a factor to trigger RelA-mediated ppGpp accumulation in the starvation adaptive response, but act as a stress challenge to the starved cells.

SpoT-mediated ppGpp accumulation has been shown to be important for carbon starvation survival (Nystrom, 1994; Ostling et al., 1995). The stationary-phase sigma factor RpoS is required for resistance to nutrient starvation, UVA radiation and oxidative stress (Eisenstark, 1998; Eisenstark et al., 1996; Hengge-Aronis, 1996; Loewen \& Hengge-Aronis, 1994). The RpoSregulated protein Dps (DNA-binding protein in starvation) is also known to be important in oxidative stress resistance, via protection of DNA against ROS attack (Almiron et al., 1992). Hence, the light-dependent lethality of the spoT, rpoS and $d p s$ mutants during fatty acid starvation may not be surprising. However, it is worthwhile to note the differences among the losses in viability during fatty acid starvation for the relA spoT mutant, the rpoS mutant and the dps mutant. The greater lethality for the relA spoT mutant in comparison to that for the rpoS mutant can be explained by the recent finding that ppGpp is required for the expression of RpoS-controlled genes in a RpoS-independent manner (Kvint et al., 2000). Furthermore, McGlynn \& Lloyd (2000) demonstrated that ppGpp plays a direct role in promoting the ability of E. coli cells to survive UVinduced DNA damage. This increased survival may be explained by the destabilization of RNA polymerase promoter open complexes, or by stalled elongation complexes (Bartlett et al., 1998; Zhou \& Jin, 1998), thereby minimizing stalled RNA polymerase blocks to 
replication fork progression and excision repair. The greater lethality of the $d p s$ mutant in comparison to that of the rpoS mutant indicates that Dps may play a more direct role in protecting cells against stress attack in starvation. This assumption is also supported by the multi-factorial regulation of Dps expression, i.e. it is activated by OxyR during exponential phase and by IHF and RpoS in stationary phase (Altuvia et al., 1994). Together, these results suggest that the fatty acid starvation adaptation of the illuminated bacterial cells requires successful defence against UV-imposed oxidative stress, and that the starvation-induced stress resistance is dependent on spoT-dependent ppGpp accumulation, as well as the upregulation of $r p o S$ and RpoS-controlled stress resistance genes such as $d p s$.

\section{Accumulation of ppGpp and fatty acid starvation survival}

The light-exposed E. coli relA spoT mutant CF1693 loses cell viability and fails to accumulate ppGpp following fatty acid starvation. However, the lightexposed E. coli relA mutant maintains cell viability and accumulates ppGpp as the wild-type strain does during fatty acid starvation. This suggests a correlation between the loss in viability and the lack of spoTdependent ppGpp accumulation. A similar correlation has been found in carbon starvation adaptation, in which ppGpp accumulation during the first few hours of starvation has a long-term effect on the survival ability for many days (Matin, 2000; Nystrom, 1994). The fatty acid starvation lethality of the E. coli relA spoT deletion mutant is not surprising, since this $\mathrm{ppGpp}^{0}$ strain is more sensitive to many other stresses, including carbon starvation and amino acid starvation (Nystrom, 1994; Xiao et al., 1991). The ' $V$. angustum' S14 spoT mutant J109 displayed threefold higher ppGpp levels and a severe loss in viability in comparison to the wild-type strain S14 during fatty acid starvation. J109 contains a Tn10 insertion in the middle of the spoT gene and exhibits higher ppGpp accumulation as well as lightdependent loss in viability during carbon starvation (Ostling et al., 1995). Therefore, the transposon insertion spoT mutant of ' $V$. angustum' S14 is different from the relA spoT deletion mutant of E. coli. Although the mechanism of the ppGpp overaccumulation in J109 is unknown, the similar transposon disruption mutants in E. coli (Sarubbi et al., 1989) suggest that it may be due to the reduced ppGppase activity of SpoT. Thus, the fatty acid starvation lethality of light-exposed ' $V$. angustum' S14 spoT mutant cells appears to depend on a greater and prolonged elevation of ppGpp levels, caused by the truncated SpoT protein.

Artificial overproduction of ppGpp by overexpression of a recombinant relA in E. coli during fatty acid starvation under light led to a marked loss in cell viability, which was analogous to the results observed for the ' $V$. angustum' S14 spoT mutant. Also, the E. coli spoT203 allele, found to reduce ppGpp degradative activity resulting in an overelevation of ppGpp levels
(Sarubbi et al., 1988), significantly exacerbates the decline in viability during fatty acid starvation under light. These results support our hypothesis that overaccumulation of ppGpp impairs the survival ability of the illuminated fatty-acid-starved cells. Apirakaramwong et al. (1999) reported a similar decline in cell viability in stationary phase due to artificial ppGpp overaccumulation. After overexpression of a recombinant constitutive relA in E. coli, a rapid increase in the levels of ppGpp was observed, accompanied by a severe loss in viability and a decrease in the RpoS level (Apirakaramwong et al., 1999). This finding is unexpected because it has been reported that RpoS synthesis is upregulated by ppGpp (Gentry et al., 1993; Lange et al., 1995). However, it suggests that the prolonged ppGpp accumulation may become toxic for cells in late-phase starvation through the reduction of RpoS levels. Since accumulation of ppGpp has the dual consequences of stimulating and inhibiting gene expression, it is likely that the proper balance of these effects must be set for an appropriate physiological response. In other words, overaccumulation of $\mathrm{ppGpp}$ may inhibit rRNA synthesis and down-regulate the protein synthetic capacity to a level which is below that required for sufficient translation of stress resistance proteins. Although the lethal effect of ppGpp overaccumulation with fatty acid starvation was more significant than that without starvation, the sole killing effect of ppGpp overproduction might not be ruled out, which was supported by recent studies (Aizenman et al., 1996; Sat et al., 2001) showing that MazEF-mediated programmed cell death is induced by the artificial overproduction of ppGpp, leading to higher concentrations than those of physiological conditions.

Based on the results presented in this study, we propose that successful fatty acid starvation survival of the lightexposed bacterial cells depends on an adaptive response, which requires appropriate spoT-dependent ppGpp accumulation, the upregulation of RpoS and hence the induction of RpoS-controlled stress resistance proteins such as Dps. Lack, or overaccumulation, of ppGpp impairs the fatty acid starvation survival of lightexposed cells. These early-phase starvation-induced proteins are able to exert prevention and/or repair of the UV-induced oxidative damage, leading to effective protection against naturally occurring weak UV radiation.

\section{ACKNOWLEDGEMENTS}

We thank Michael Cashel and Roberto Kolter for E. coli mutant strains. This work was supported by an Australian Research Council grant.

\section{REFERENCES}

Aizenman, E., Engelberg-Kulka, H. \& Glaser, G. (1996). An Escherichia coli chromosomal 'addiction module' regulated by ppGpp: a model for programmed cell death. Proc Natl Acad Sci US A 93, 6059-6063. 
Albertson, N. H., Nystrom, T. \& Kjelleberg, S. (1990). Exoprotease activity of two marine bacteria during starvation. Appl Environ Microbiol 56, 218-223.

Almiron, M., Link, A. J., Furlong, D. \& Kolter, R. (1992). A novel DNA-binding protein with regulatory and protective roles in starved Escherichia coli. Genes Dev 6, 2646-2654.

Altuvia, S., Almiron, M., Huisman, G., Kolter, R. \& Storz, G. (1994). The $d p s$ promoter is activated by OxyR during growth and by IHF and S in stationary phase. Mol Microbiol 13, 265-272.

Apirakaramwong, A., Kashiwagi, K., Raj, V. S., Sakata, K., Kakinuma, Y., Ishihama, A. \& Igarashi, K. (1999). Involvement of ppGpp, ribosome modulation factor, and stationary phasespecific sigma factor $\sigma^{\mathrm{S}}$ in the decrease in cell viability caused by spermidine. Biochem Biophys Res Commun 264, 643-647.

Bachmann, B. J. \& Low, K. B. (1984). Linkage map of Escherichia coli K-12. Edition 6. Microbiol Rev 44, 1-56.

Bartlett, M. S., Gaal, T., Ross, W. \& Gourse, R. L. (1998). RNA polymerase mutants that destabilize RNA polymerase-promoter complexes alter NTP-sensing by $r r n \mathrm{P} 1$ promoters. J Mol Biol 279, 331-345.

Bohannon, D. E., Connell, N., Keener, J., Tormo, A., EspinosaUrgel, M., Zambrano, M. M. \& Kolter, R. (1991). Stationary-phaseinducible 'gearbox' promoters: differential effects of katF mutations and the role of $\sigma^{70}$. J Bacteriol 173, 4482-4492.

Cashel, M. (1994). Detection of (p)ppGpp accumulation patterns in Escherichia coli mutants. Methods Mol Genet 3, 341-356.

Cashel, M. (2000). Stringent response. In Encyclopedia of Microbiology, vol. 4, pp. 467-477. Edited by J. Lederberg. San Diego, CA: Academic Press.

Cashel, M., Gentry, D. R., Hernandez, V. J. \& Vinella, D. (1996). The stringent response. In Escherichia coli and Salmonella: Cellular and Molecular Biology, 2nd edn, pp. 1458-1496. Edited by F. C. Neidhardt and others. Washington, DC: American Society for Microbiology.

Cebula, T. A., Henrikson, E. N., Hartman, P. E. \& Biggley, W. H. (1995). Reversion profiles of coolwhite fluorescent light compared with far ultraviolet light-homologies and differences. Photochem Photobiol 61, 353-359.

Connell, N., Han, Z., Moreno, F. \& Kolter, R. (1987). An Escherichia coli promoter induced by the cessation of growth. Mol Microbiol 1, 195-201.

DiRusso, C. C. \& Nystrom, T. (1998). The fats of Escherichia coli during infancy and old age: regulation by global regulators, alarmones and lipid intermediates. Mol Microbiol 27, 1-8.

Eisenstark, A. (1989). Bacterial genes involved in response to nearultraviolet radiation. Adv Genet 26, 99-147.

Eisenstark, A. (1998). Bacterial gene products in response to nearultraviolet radiation. Mutat Res 422, 85-95.

Eisenstark, A., Calcutt, M. J., Becker-Hapak, M. \& Ivanova, A. (1996). Role of Escherichia coli rpoS and associated genes in defence against oxidative damage. Free Radic Biol Med 21, 975-993.

Fernandez, R. O. \& Pizarro, R. A. (1999). Pseudomonas aeruginosa UV-A-induced lethal effect: influence of salts, nutritional stress and pyocyanine. J Photochem Photobiol B Biol 50, 59-65.

Flardh, K., Cohen, P. S. \& Kjelleberg, S. (1992). Ribosome exists in large excess over the apparent demand for protein synthesis during carbon starvation in marine Vibrio sp. strain CCUG 15956. J Bacteriol 174, 6780-6788.

Flardh, K., Axberg, T., Albertson, N. H. \& Kjelleberg, S. (1994). Stringent control during carbon starvation of marine Vibrio sp. strain S14: molecular cloning, nucleotide sequence, and deletion of the relA gene. J Bacteriol 176, 5949-5957.

Gentry, D. R. \& Cashel, M. (1995). Cellular localisation of the Escherichia coli SpoT protein. J Bacteriol 177, 3890-3893.

Gentry, D. R., Hernandez, V. J., Nguyen, L. H., Jensen, D. B. \& Cashel, M. (1993). Synthesis of the stationary-phase sigma factor $\sigma^{\mathrm{S}}$ is regulated by ppGpp. J Bacteriol 175, 7982-7989.

Heath, R. J., Jackowski, S. \& Rock, C. O. (1994). Guanosine tetraphosphate inhibition of fatty acid and phospholipid synthesis in Escherichia coli is relieved by overexpression of glycerol-3phosphate acyltransferase ( $p l s B)$. J Biol Chem 269, 26584-26590.

Hengge-Aronis, R. (1996). Regulation of gene expression during entry into stationary phase. In Escherichia coli and Salmonella: Cellular and Molecular Biology, 2nd edn, pp. 1497-1512. Edited by F. C. Neidhardt and others. Washington, DC: American Society for Microbiology.

Hoben, H. J. \& Somsegaran, P. (1982). Comparison of the pour, spread, and drop plate methods for enumeration of Rhizobium spp. in inoculants made from presterilized peat. Appl Environ Microbiol 44, 1246-1247.

Jagger, J. (1981). Near-UV radiation effects on microorganisms. Photochem Photobiol 34, 761-768.

Jeffrey, W. H., Aas, P., Lyons, M. M., Coffin, R. B., Pledger, R. J. \& Mitchell, D. L. (1996). Ambient solar radiation-induced photodamage in bacterioplankton. Photochem Photobiol 64, 419-427.

Joux, F., Jeffrey, W. H., Lebaron, P. \& Mitchell, D. L. (1999). Marine bacterial isolates display diverse responses to UV-B radiation. Appl Environ Microbiol 65, 3820-3827.

Kjelleberg, S., Albertson, N., Flardh, K., Holmquist, L., JouperJaan, A., Marouga, R., Ostling, J., Svenblad, B. \& Weichart, D. (1993). How do non-differentiating bacteria adapt to starvation? Antonie Leeuwenhoek 63, 333-341.

Kramer, G. F., Baker, J. C. \& Ames, B. N. (1988). Near-UV stress in Salmonella typhimurium: 4-thiouridine in tRNA, ppGpp, and ApppGpp as components of an adaptative response. J Bacteriol 170, 2344-2351.

Kvint, K., Farewell, A. \& Nystrom, T. (2000). RpoS-dependent promoters require guanosine tetraphosphate for induction even in the presence of high levels of $\sigma^{\mathrm{s}}$. J Biol Chem 275, 14795-14798.

Lange, R., Fischer, D. \& Hengge-Aronis, R. (1995). Identification of transcriptional start sites and the role of $\mathrm{ppGpp}$ in the expression of $r p o S$, the structural gene for the sigma $S$ subunit of RNA polymerase in Escherichia coli. J Bacteriol 177, 4676-4680.

Loewen, P. C. \& Hengge-Aronis, R. (1994). The role of the sigmafactor $\mathrm{S}(\mathrm{KatF})$ in bacterial global regulation. Annu Rev Microbiol 48, 53-80.

Loewen, P. C., Hu, B., Strutinsky, J. \& Sparling, R. (1998). Regulation in the rpoS regulon of Escherichia coli. Can J Microbiol 44, 707-717.

McCann, M. P., Kidwell, J. P. \& Matin, A. (1991). The putative $\sigma$ factor KatF has a central role in development of starvationmediated general resistance in Escherichia coli. J Bacteriol 173, 4188-4194.

McGlynn, P. \& Lloyd, R. G. (2000). Modulation of RNA polymerase by (p)ppGpp reveals a RecG-dependent mechanism for replication fork progression. Cell 101, 35-45.

Marden, P., Tunlid, A., Malmcrona-Friberg, K., Odham, G. \& Kjelleberg, S. (1985). Physiological and morphological changes during short term starvation of marine bacterial isolates. Arch Microbiol 142, 326-332.

Marden, P., Nystrom, T. \& Kjelleberg, S. (1987). Uptake of leucine 
by a marine Gram-negative heterotrophic bacterium during exposure to starvation conditions. FEMS Microbiol Ecol 45, 233-241.

Matin, A. (1991). The molecular basis of carbon-starvationinduced general resistance in Escherichia coli. Mol Microbiol 5, 3-10.

Matin, A. (2000). Bacterial starvation. In Encyclopedia of Microbiology, vol. 4, pp. 394-403. Edited by J. Lederberg. San Diego, CA: Academic Press.

Moche, M., Schneider, G., Edwards, P., Dehesh, K. \& Lindqvist, Y. (1999). Structure of the complex between the antibiotic cerulenin and its target, $\beta$-ketoacyl-acyl carrier protein synthase. $J$ Biol Chem 274, 6031-6034.

Neidhardt, F. C., Bloch, P. L. \& Smith, D. F. (1974). Culture medium for enterobacteria. J Bacteriol 119, 736-747.

Nystrom, T. (1994). Role of guanosine tetraphosphate in gene expression and the survival of glucose or seryl-tRNA starved cells of Escherichia coli K12. Mol Gen Genet 245, 355-362.

Nystrom, T., Marden, P. \& Kjelleberg, S. (1986). Relative changes in incorporation rates of leucine and methionine during starvation survival of two bacteria isolated from marine waters. FEMS Microbiol Ecol 38, 285-292.

Omura, S. (1981). Cerulenin. Methods Enzymol 72, 520-532.

Ostling, J., Goodman, A. \& Kjelleberg, S. (1991). Behaviour of IncP-1 plasmids and a mini $u$ transposon in a marine Vibrio strain: isolation of starvation inducible lac operon fusions. FEMS Microbiol Ecol 86, 83-94.

Ostling, J., Flardh, K. \& Kjelleberg, S. (1995). Isolation of a carbon starvation regulatory mutant in a marine Vibrio strain. J Bacteriol 177, 6978-6982.

Ostling, J., Holmquist, L. \& Kjelleberg, S. (1996). Global analysis of the carbon starvation response of a marine Vibrio species with disruptions in genes homologous to relA and spoT. J Bacteriol 178, 4901-4908.

Sambrook, J., Fritsch, E. F. \& Maniatis, T. (1989). Molecular Cloning: a Laboratory Manual, 2nd edn. Cold Spring Harbor, NY: Cold Spring Harbor Laboratory.
Sarubbi, E., Kenneth, E., Rudd, K. E. \& Cashel, M. (1988). Basal ppGpp level adjustment shown by new spoT mutants affect steady state growth rates and $r r n A$ ribosomal promoter regulation in Escherichia coli. Mol Gen Genet 213, 214-222.

Sarubbi, E., Rudd, K. E., Xiao, H., Ikehara, K. \& Cashel, M. (1989). Characterization of the spoT gene of Escherichia coli. J Biol Chem 264, 15074-15082.

Sat, B., Hazan, R., Fisher, T., Khaner, H., Glaser, G. \& EngelbergKulka, H. (2001). Programmed cell death in Escherichia coli: some antibiotics can trigger mazEF lethality. J Bacteriol 183, 2041-2045.

Seyfzadeh, M. (1994). Regulation of ribosomal RNA synthesis in Escherichia coli by a novel guanosine tetraphosphate induction pathway. PhD thesis, University of California.

Seyfzadeh, M., Keener, J. \& Nomura, M. (1993). spoT-dependent accumulation of guanosine tetraphosphate in response to fatty acid starvation in Escherichia coli. Proc Natl Acad Sci US A 90, 11004-11008.

Srinivasan, S. \& Kjelleberg, S. (1998). Cycles of famine and feast - the starvation and outgrowth strategies of a marine Vibrio. $J$ Biosci 23, 501-511.

Svitil, A. L., Cashel, M. \& Zyskind, J. W. (1993). Guanosine tetraphosphate inhibits protein synthesis in vivo. J Biol Chem 268, 2307-2311.

Thiam, K. \& Favre, A. (1984). Role of the stringent response in the expression and mechanism of near-ultraviolet growth delay. Eur J Biochem 145, 137-142.

Xiao, H., Kalman, M., Ikehara, K., Zemel, S., Glaser, G. \& Cashel, M. (1991). Residual guanosine $3^{\prime}, 5^{\prime}$-bispyrophosphate synthetic activity of relA null mutants can be eliminated by spoT null mutations. J Biol Chem 266, 5980-5990.

Zhou, Y. N. \& Jin, D. J. (1998). The $r p o B$ mutants destabilizing initiation complexes at stringently controlled promoters behave like 'stringent' RNA polymerases in Escherichia coli. Proc Natl Acad Sci U S A 95, 2908-2913.

Received 8 June 2001; revised 3 October 2001; accepted 5 October 2001. 